Western Washington University Western CEDAR

\title{
Photovoice as Micro-Invitation: A Case Study of High School Im/ migrant Youth Disrupting Everyday Forms of Racism
}

\author{
Kevin Roxas \\ Western Washington University, kevin.roxas@wwu.edu \\ Verónica Vélez \\ Western Washington University, Veronica.Velez@wwu.edu
}

Follow this and additional works at: https://cedar.wwu.edu/woodring_dei

Part of the Education Commons

\section{Recommended Citation}

Roxas, K., \& Vélez, V. (2019). Photovoice as Micro-Invitation: A Case Study of High School Im/migrant Youth Disrupting Everyday Forms of Racism. The High School Journal, 102(4), 267-282.

This Article is brought to you for free and open access by the Woodring College of Education at Western CEDAR. It has been accepted for inclusion in Woodring Scholarship on Diversity, Equity, Inclusion by an authorized administrator of Western CEDAR. For more information, please contact westerncedar@wwu.edu. 
Photovoice as Micro-Invitation: A Case Study of High School $\mathrm{Im} /$ migrant Youth Disrupting Everyday Forms of Racism

Kevin Roxas

Western Washington University

Verónica Vélez

Western Washington University

Racial microaggressions describe how People of Color experience daily racial assault in seemingly minor, but nonetheless insidious ways. The photovoice project highlighted here demonstrates the varied ways in which im/migrant high school students in one community challenged everyday microaggressions by making clear how they one community challenged everyday microaggressions by making clear how the respond, and interrupt racist discourses. We introduce the concept of micro-invitation to describe strategic efforts to build collective forms of resistance. We argue that microinvitations, as a both a theoretical and pedagogical intervention, helps us better understand how marginalized youth, in this case im/migrant youth, resist dominant understandings of who they are and invite others to mediate and dismantle everyday forms of racism.

Keywords: racial microaggressions, im/migrant students, micro-invitations

\section{Introduction}

Racial microaggressions are everyday forms of racism (Pierce, 1970; Solorzano, Ceja \& Yosso, 2000). They describe how People of Color ${ }^{[1]}$ experience racial assaults in seemingly minor, but nonetheless insidious ways. The cumulative effect of these microaggressive acts can result in what Smith (2004, 2008a, 2008b, 2010) refers to as racial battle fatigue, defined as the social, psychological, and physiological stress and response to everyday racism. The sum total of everyday racism has a numbing and disempowering effect on People of Color that is seemingly innocuous yet over time harms one's identity and sense of self-worth (Smith, Yosso, \& Solorzano, 2006).

Research is emerging that describes how Communities of Color resist and respond to racial microaggressions (Pérez-Huber \& Solorzano, 2015). Deepening our

\footnotetext{
We intentionally place a "/" between "im" and "migrant" to disrupt the normalized asymmetrical relationship assumed im/migrants have with the U.S. under mainstream discourse. This normalized understanding often serves to legitimate notions that im/migrants move to the U.S. in pursuit of the "American dream" and often mask the underlying socio-poltical and econmys migrant back and forth from the U.S. and their home countries, send remittances to family members outside of the U.S., and/or disidentify with citizenship structures and efforts to assimilate (Morissey, 2013). In an effort to more accurately represent these varied and complex realities, we chose to use "im/migrant" in lieu of "immigrant" as a grammatical move towards justice.

(c) 2019 The University of North Carolina Press
} 
understanding of these forms of resistance is critical, especially for teachers who can intervene pedagogically to support students' sense of agency and power within everyday strumined and studied within the foritical race research, we wish to examine the field of edwcation, particularly within critical race sule we nuanced ways in which $\mathrm{im} /$ migrant high school students call out for their peers, teachers, and community members to authentically understand their lives,

The research highlighted here demonstrates the ways in which im/migrant high school The revery microaggressions by making clear how they wanted fellow students, teachers, and other members of society to acknowledge, respond, and interrupt racist discourses. While the larger study sought to assess the benefits of photovoice, a form of participatory action research in which participants share about their lives through photographs and personal narratives, findings also revealed intentional efforts on behalf of high school im/migrant youth to disrupt racist depictions of themselves and their communities. This led us to ask the following: 1) How are $\mathrm{im} /$ migrant youth making sense of dominant discourses about them, their families, and their communities?; 2) What themes or elements define the counterstories these youth are employing to interrupt these dominant depictions? and; 3) How are im/migrant youth using discursive counter-strategies to build collective forms of resistance?

To address these questions, we begin by contextualizing our work within literature that critically explores the experiences of im/migrant youth in schools, particularly how racial microaggressions mediate their educational journeys. Because the youth in this study sought to build collective forms of resistance, particularly with school agents, we also highlight the importance of teachers as culturally responsive advocates for social change. We then introduce photovoice as the chosen methodology for this study, as well as the research site and participants. Next, we provide our findings, highlighting several themes and defining corresponding examples that respond to the question guiding this study. We introduce the concept of micro-invitations to describe strategic efforts on behalf of the im/migrant youth in this study to build collective forms of resistance. We discuss how these micro-invitations, as both a theoretical and pedagogical intervention, can deepen our insight about how marginalized youth, in thi case im/migrant youth, resist dominant understandings of who they are and invite others to dismantle everyday forms of racism.

Challenging Deficit Discourses and Racial Microagressions About Im/Migrant Youth $\mathrm{Im} /$ migrant youth continue to enroll in U.S. public schools at an unprecedented rate (Krogstad \& Fry, 2014) ${ }^{[2]}$ These youth arrive in schools with a wide range of educational experiences from their home countries and differing levels of academic preparation (Decapua, Smathers \& Tang, 2007; Suárez-Orozco \& Suárez-Orozco, 1995 Suárez-Orozco \& Suárez-Orozco, 2009). As they transition, they often face several obstacles. For example, im/migrant students at the high school level face a host of obstacles in their socio-emotional growth including the impact of being bullied, insecurity in their identity formation because of an ambivalent context of reception in local schools, and a lack of perceived support from and connection to educators within their schools (Suárez-Orozco \& Suárez-Orozco, 2001). For im/migrant youth,

2 "People of Color" is intentionally capitalized to reject the standard grammatical norm. Capitalization is used as a means to empower and represents a grammatical move toward justice. This rule will also apply to 268 these struggles are exacerbated by racism and other forms of hostility (Fergus, 2009; Holdaway \& Alba, 2009; Suárez-Orozco \& Suárez-Orozco, 2001).

One way in which this racial hostility is experienced is in the form of racial microaggressions. Critical race scholars have provided a powerful framework to expose, understand, and resist this discursive violence in schools (Pérez Huber \& Solorzano, 2015). This analysis starts by underscoring how majoritarian stories support the status quo by furthering a set of ideologies and beliefs in the inherent superiority of whites over People of Color. These narratives utilize notions of meritocracy and colorevasiveness ${ }^{[3]}$ to reinforce an investment in whiteness and normalize it as dominant, legitimate, and treasured in U.S. society (Delgado \& Stefancic, 2001; Gillborn, 2006). Gillborn (2006) highlights the normalization of whiteness through the use of majoritarian stories when he states ". . . the racialized nature of politics, policing, education, and every other sphere of public life is so deeply ingrained that it has become normalized - unremarked, and taken for granted" (p. 319).

To respond to majoritarian stories, People of Color use counterstories to provide a different version of the story based upon the strengths and assets, or what Yosso (2005) refers to as community cultural wealth, evident in their homes and communities. These counterstories speak back to the racially deficit narratives that seek to position People of Color as inferior. Counterstories are a means by which members of groups that have been historically marginalized can present an accurate rendition of their lived experience and empower themselves in that story-telling process. Solorzano and Yosso (2002) define counterstorytelling as ". . . a method of telling the story of those experiences that not often told (i.e. those on the margins of society) and a tool for analyzing and challenging the stories of those in power and whose story is a natural part of the dominant discourse - the majoritarian story" (p. 475).

An important focus for teachers serving im/migrant youth is to explicitly challenge deficit discourses and racial microaggressions. This includes, but is not limited to, negative stereotypes relating to race, language, immigration, and education (Cammarota \& Aguilera, 2012), which often collide for im/migrant youth, particularly in school settings (Roxas \& Gabriel, 2016) and within popular media (Yosso, 2002). Creating opportunities for teachers to critically intervene to disrupt these common yet problematic narratives allows them to develop a language and a process for generating counterstories that have the potential to transform their frames of thinking and critically engage youth that all too frequently have been alienated by schools (Freire, 1970; McInerney, 2009; Sanchez, 2010; Smith, 1999).

Teachers as Culturally Responsive Advocates for Social Change

There are numerous ways teachers can intervene pedagogically to challenge mainstream discourses about im/migrants in their classrooms. For example, providing creative opportunities for students to narrate stories about their experiences at school and in their local communities can serve to further their development as writers and story-tellers of their lives, families, cultures, and histories (Baldridge, Hill, \& Davis, 2011; Booth \& Sheehan, 2008; Doda \& Knowles, 2008; Ho, Rochelle \& Yuen, 2011; Moje, 2008). Through these opportunities, students can develop new ways to express

We use "color-evasiveness" (Stubblefield, 2005) in lieu of "color-blindness," the more traditional term for this ideology to 1) problematize an assumption that equates blindness with ignorance that, by extension from the figurative to the literal, inaccurately conveys and distorts the unique way blind individuals interact with the world and, 2) rethink and remove able-ist language from critical race discourse as core to our explicit efforts toward social justice in all aspects of our work, particularly in research and scholarship
(Annamma, Morrison, and Jackson, 2014). 
themselves that highlight their understanding of "access, dissent, and liberation" (Morrell, 2007). Students are better equipped to articulate how teachers and others can better serve their needs as learners and as developing adolescents (Eldsen-Clifton, 2006; Zenkov, 2009).

The call for teachers to be attentive to and conscious of the different cultures and ways of being for their im/migrant students has been written extensively within the field of education (Gay, 2010; Villegas \& Lucas, 2007). However, as im/migrant students continue to increasingly enroll in U.S. public schools, teachers must consider further how they can build critical understandings of im/migrant youth in ways that are authentic, racially and culturally competent, and ultimately humanizing for all participants in schools (Suárez-Orozco, Pimentel, and Martin, 2009; Paris, 2011). It is critical for teachers to create opportunities for students to develop strategies that build their agency for initiating social change in their schools and local communities (Jimenez \& Rose, 2010; Seidl, 2007; Torre, Fine, Alexander, \& Genao, 2007).

By actively creating a platform for im/migrant students to share their stories, teachers further a positive classroom environment as well as develop for themselves a more agentic perspective on their work as teachers (Duncan-Andrade, 2005; Murrell, 2006 Esposito \& Swain, 2009). Through the use of the arts, visual imagery, and collaborative inquiry, teachers and students can name and envision classroom and school environments where students, in response to daily negative stereotypes, can imagine themselves in positive and productive ways (Bell \& Desai, 2011; Duncan-Andrade, 2006; Baszile, 2009).

\section{Methodology: Photovoice}

Teachers can help students narrate their stories through the use of a participatory action research project called photovoice. Participatory action research has the potential to nurture and foster student agency to seek out answers to questions that vex munities, and to share the findings of their research with fellow students, parents, teachers, and members of the local community (Ozer, Ritterman, \& Wanis, 2010; Stovall \& Delgado, 2009). Participatory action research offers transformative possibilities in that it asks participants to take action and create change within existing systems (Foster-Fishman, Law, Lichty, \& Aoun, 2010; Smith, Davis, \& Bhowmik, 2010; Streng, Rhodes, Ayala, Eng, Arceo, \& Phipps, 2004).

Photovoice is a form of participatory action research in which participants are guided through a process in which they share about their lives through photographs they take, through accompanying narrative text they write, and through public exhibitions of posters they create that combine both photographs and text. Originally used within the field of public health to provide opportunities for marginalized populations to express themselves (Wang, 1999), photovoice has been used to engage members of the homeless community, youth in after-school organizations, and pregnant and parenting teens (Strack, Magill, \& McDonagh, 2004; Wang, Cash, \& Powers, 2000) and has increasingly been used within school classrooms (Ewald \& Lightfoot, 2001; Ho, Rochelle, \& Yuen, 2011; Kaplan \& Howes, 2004; Zenkov \& Harmon, 2009).

Photovoice facilitates the development of communication skills among participants as they narrate their lives. The process itself requires participants to think deeply about who they are, identify the strengths and community cultural wealth of their homes, schools, and local communities, and describe what kinds of obstacles they face. Through this process, participants realize the power they have to tell stories that matter to them, educate others within their schools about who they are, and advocate for themselves and members of their cultural groups (Delgado, 2012; Gosessling \& Doyle, 2009; Lambert, 2013; Lutrell, 2010)

A strong sense of intentional community is also forged among participants as they begin to share personal photos, stories, and memories (Bagnoli, 2009; Bates, 2010 Ewald \& Lightfoot, 2001). As participants analyze visual imagery and deepen their understanding for one another, they begin to see how photography, narrative, and photovoice projects can serve as a way to interrogate their experiences in schools and serve as a catalyst for social action and change (Griebling, Vaughn, Howell, Ramstetter, \& serve as a catalyst for social action and change (Griebling, Vaughn, Howell, Ramstetter, \&
Dole, 2013; Gubrium \& Torres, 2013; Kaplan \& Howes, 2004). As they share their work, it sparks important and critical discussions among the local community that serves as audience.

The year-long photovoice project described in this article was created to provide teachers, counselors, administrators and support staff in the Mountain Valley Schoo District (MVSD) ${ }^{4]}$ win information about the district's im/migrant students and their families. The data collection process sought to engage im/migrant students and famfamilies. The data collection process sought to engage im/migrant students and fam-
ilies in the MVSD through culturally responsive methods, inviting students and families to share stories of their move to the MVSD through photographs, narratives, interviews, and community engagement.

This article reports findings from work with im/migrant students enrolled at Passages High School (PHS), one of the school-based sites of a larger photovoice project conducted with im/migrant students and parents within the MVSD. All PHS participants were enrolled in sheltered English classes based on their level of proficiency in English as a Second Language (ESL). The research team created and conducted workshop sessions with im/migrant students at PHS to better understand their experiences in school as students and members of the local community. Students were asked to express themselves through photographs, through which they reflected on the challenges and opportunities they faced as recent arrivals within the school district. To better facilitate the workshop sessions, the research team was designed to include a cross-representation of faculty researchers and paraprofessionals from the school district who spoke languages most commonly used by students and families in MVSD, including Spanish and Arabic.

Participants and Setting

Twenty-one high school students participated in this study. All students were enrolled TSL students at Passages High School (PHS) and had arrived in the U.S. within the last two years at the time of the study. While many of the student participants had emigrated from Mexico with their families or by themselves to live with aunts and uncles in Mountain Valley, students came from a wide variety of countries including the Philippines, Korea, Haiti, Iraq, Yemen, and Saudi Arabia. All students were between 15 and 19 years of age.

Mountain Valley is located in the Mountain West region of the United States, about 1 hour from Denver, Colorado. The areas surrounding Mountain Valley have experienced ongoing $\mathrm{im} /$ migration as a result of growing industries and jobs in agriculture, ranching, and meat- packing. While Colorado's Latina/o population continues to grow, $\mathrm{im} /$ migration from other countries around the world also continues to expand to match the labor needs of the region.

${ }^{4}$ All names of places and people have been made anonymous. 
Procedure

All PHS student participants attended six 3-hour sessions in which they analyzed visual images, discussed and practiced principles of photography and design, took photographs of important images and moments in their lives, and wrote text to ac company their photographs. During these weekly meetings, project facilitators sought to create a welcoming environment that allowed these high school students the opportunity to share about process, facilitators created a supportive space in which students could identify how the school, its teachers, its counselors and their peers can create a positive environment for them to learn.

In between classes, high school participants were asked to take photographs at home and at their school to document their lives and hopes for their educational futures. Students took these photographs during the week and then brought their memory cards and cameras to weekly meetings where the photographs were digitally displayed. Participants then took turns discussing the visual imagery and the meaning behind each. Once student participants felt comfortable taking photographs and writing about their personal experiences and stories, workshop facilitators asked them to create and design their own photovoice posters.

The project culminated with a month-long exhibition of the work created by project participants, including poster presentations by im/migrant students and their parents. A special reception was held half-way through the exhibition with approximately 250 audience members and project participants to celebrate the overall project, share posters, and invite a community discussion about the work of all photovoice project participants. The high school student group was part of a larger photovoice project conducted within the school district that included work with $\mathrm{im} /$ migrant parents and students from the elementary, middle, and high school levels.

Data Analysis

Participant narratives embedded within the photovoice project posters and shared during individual interviews were analyzed using constant comparison analysis (Corbin \& Strauss, 2008). Individual incidents within the data were compared and contrasted with other incidents within the study. Related themes were grouped together to aid in the understanding of the experiences of participants across multiple photos, written narratives, and individual interviews (Leech \& Onwuegbuzie, 2008). Three levels of coding were used in the data analysis process including open coding, axial coding, and selective coding. These codes were used to write frequent memos that identified evidence-based themes represented by participants within this research project (Charmaz, 2006; Corbin \& Strauss, 2008).

Results

Theme 1: Reported Feelings of Pain, Loneliness, and Disconnectedness. One recurring theme that cut across student participants was that of feeling pain, loneliness, and disconnectedness. Participants reported how difficult the transition was to their new school and to the city of Mountain Valley from their countries of origin and emphasized their desire for teachers, students and community members to better understand and appreciate the challenges they faced.

Eduardo, a student who emigrated from Mexico with his family to Passages High School, explained how difficult it was to move to the U.S. and to his new high school. He wrote, "Being from an im/migrant family is hard. Why? Because, everything is new-a new people, a new culture, a new language. Every day for me is a challenge but with the help of my family, friends and teachers I can overcome anything in my way."
His analysis of the photographs in his poster were focused on all the different new things he had to learn, such as meeting new people, adjusting to a new culture, and learning English as a second language. He stressed the struggle in learning all of these new things as he tried to do well both academically and socially in school.

Other students tried to capture the pain of loss before arriving in the U.S. Ahmed, student from Iraq, wrote about how his dad was captured and how he thought he had been killed: He writes, "The hardest challenge I have ever faced was during the Iraq War when the terrorists took my dad for many years. For the first time when I came to the United States we got a call from my family in Iraq and I heard my dad saying 'I am still alive.' I was so happy when I heard those words!" Riyam, another student from Iraq, shares a similar story about how his father was killed and how he and the rest of his family had to flee Iraq and come to the U.S. as refugees. He wrote:

A challenge that I have faced is when I left my uncle in Iraq. My mom, brother, sister and I came here to the United States as refugees. My father had been taken by terrorists and my uncle became like a father to me. This was the hardest challenge I have ever faced. I put his [my father's] picture here in my poster to let people know how much I love him.

Both Ahmed and Riyam faced many difficulties before arriving in the U.S., including the capture and persecution of family members in Iraq and also the pain of separation from loved ones.

Being forced to leave their home country, leave behind people they loved, and tran sition to a new and unfamiliar place brought tremendous pressure and additional stress upon their lives as they struggled to adapt to life as a language minority student in the Mountain Valley School District.

Gertride describes the difficult times she faced in Haiti when her mom died and her family realized they had no money to support her. They faced the difficult decision to put her up for adoption. She writes:

One thing people wouldn't know about me by looking at me is that I have two families. I moved here after my mother died, and my family couldn't take care of me. They didn't have the money to do it. When my mother died, I was heartbroken to know that I lost the most important woman in my life. I was only seven years old when that happened. I was with my dad when my mom died and that was the hardest part of it because I didn't get to spend time with her. My sisters wanted to take care of me but they couldn't because they had kids to take care of and they didn't have the money, so one of my aunts took me to an orphanage and that is when I got adopted by a beautiful family. It was really exciting for me because I knew now I had a new family that would take care of me and I would be safe, but it was sad to know that I was leaving my Haitian family, my country and my friends, but they wanted me to go to the U.S. because they wanted me to have a better life.

Only after moving to the U.S. did she learn that her dad had also died shortly after she left.

Upon receiving this news, she didn't want to live in the U.S. anymore, but wanted to return but for now is thankful for her adoptive family and others who have shown support. She writes:

It was hard for me when I lost my mom and dad. I didn't want to stay in [state] any more. I wanted to go back to Haiti and see my family. I haven't been back to Haiti 
yet. But one day I will and when I do I will be very happy to see my family. It has been really hard to not see my family for almost 4 years. But I will see them before finish high school. And when I am done with college I will go back and stay and help my family, my people and country.

Despite all the challenges she faced, Gertride believes strongly in the power of her experiences in school. For Gertride, investing in her education will provide her the skills and knowledge to return to Haiti to help her "family, people, and country."

Joel, a student from Mexico, invites others to accept him for who he is, despite being "looked down upon." He shares, "I believe that people see im/migrants and they look down on them just because they weren't born in the United States. People should understand that just because im/migrants are born in a different country it doesn't make them different, we are just the same as you are." He later goes on to say, "people pay too much attention to other people and what their skin color is and I feel like that should stop. People should stop worrying about what the skin color of the person thei talking to is and just learn to get along with everybody because when it comes down to it we are all humans and we all have that in common." Joel is extending an invitation for others to disrupt the dominant perception, and subsequent treatment, of $\mathrm{im} /$ migrants and People of Color by making explicit reference to the similarities, rather than the differences, between individuals. These subtle invitations, or microinvitations, are interventions to recast how Immigrant of Colors are viewed by mainstream society. His plea to humanize the im/migrant condition directly counters the discourse of illegality and "alien-ness" prevalent in mainstream narratives about Mexican im/migrants.

Many of the students in the project shared the struggles they faced in life before coming to the U.S. and the obstacles they faced in their resettlement in their new schools and communities. The students also shared quite clearly the different ways in which they felt pain, loneliness and disconnectedness and their wish for others to hear and understand their stories not to generate pity, but rather to render their lives and those of their families as complex and contextual. They sought to humanize and disrupt the distorted narratives they understood as prevalent about who they are as im/migrants. These actions reflect a critical race praxis in two important ways. The first is an understanding of unjust and oppressive conditions that lead to pain, loneliness, and disconnectedness from the lived experiences of the youth in this study. The second is resistance to dominant frameworks that depict Communities of Color in a deficit light by providing alternative frames, or counterstories, grounded in the lives of these youth (Solorzano \& Yosso, 2002)

Theme 2: Desire for acceptance. Many high school participants also shared comments in their photovoice projects and interviews about their desire for greater acceptance into the school community. Despite sharing powerful stories of how they felt marginalized, students also clearly expressed a longing for their teachers and peers to accept them as they are and to welcome them in as new members of the school and local community.

Student participants all shared how they wanted their teachers and fellow classmates to know how difficult it was to make the adjustment to a new country and learn a new language, new school system, and new culture. Their yearning for support in this transition was clear and powerful. Hanan, a student from Yemen, writes, "I want the people to know that it is hard to move from place to place, country to country. Also it's hard to learn another language. The other thing I want people to know about is to be nice to the im/migrant students. Because they need to have friends and to feel they are in their countries." He points out that the physical movement from "place to place, country to country" has been challenging, but the difficulty of learning a second language and making new friends is just as much a struggle.

In a similar way, Lizeth, a student from Mexico, writes, "People can support English Language Learners by not laughing at us when we speak English. The most challenging part of being an ELL is that we have to understand English even if we don't know it at first." The experience of being laughed at because of pronunciation, word choice, or lack of confidence in English invokes fear and hesitation for many language minority students like Lizeth. It underscores the intersection of oppressive realities that many $\mathrm{im} /$ migrant students facing including language marginalization, racial discrimination, and gender bias. In this example, Lizeth makes powerfully clear how schools position $\mathrm{im} /$ migrants as marginal by normalizing English-dominant discourses. Her challenge to "understand" when she doesn't know the language highlights the expectation of $\mathrm{im} /$ migrant students to adapt quickly and the consequences when they don't. Her plea to teachers and peers to "not laugh" at her and other ELL students makes reference to this expectation and Lizeth's desire for acceptance, regardless of her level of English proficiency.

Mohammed, a student from Yemen, writes that he likes school and that he studies many hours each night to do well. However, despite all of the hours he puts into his homework and learning English, he feels that, “....the most challenging part of school is contact with people. It is hard to communicate with people because I am still learning English. It is easier to talk with teachers than students because they are patient with me. They wait for me to translate from Arabic to English in my head." Mohammed's statements are important because he points out how difficult it is to communicate with his fellow students as compared to his teachers. He underscores how students in his classes do not provide him enough time to process their statements and to prepare what he wants to say in response. His frustration with trying to communicate with his peers is alleviated somewhat by teachers who provide him the extra time to translate what he hears. His call for patience among peers as he becomes fluent in English is an invitation to understand his struggles as an im/migrant student learning the conventions of new language.

Ruben shares similar concerns to Mohammed, but discusses the necessity of persistence because "you have teachers and friends at school those are the most important thing that you have because they are the ones how help you to keep going and become successful." His point about persevering and continuing to try and find people who will support him takes an intriguing turn when he writes, "Here is something people wouldn't know about me; I'm scared of girls! When I talk to them I think they are going to make fun of me and the other thing is that I only can speak English with my friends but I am afraid to speak English with white people." Ruben's concerns are compounded by his worry that they will make fun of him because of his emerging proficiency in English. He tellingly only speaks English with his other friends from his ELL classes because he is "afraid to speak English with white people." Despite these challenges, Ruben knows he has to keep trying to make friends and find supportive people in his life. He writes, "Sometimes when you are an im/migrant you do not have the same opportunities in school but we have to overcome those challenges, don't matter how hard they are." 
Similar to Joel, Aracely shared, "What I want people to know about im/migrant students and families in this country is that your skin color, culture or beliefs doesn' matter. We are all the same and we have to be treated equal. Also being part of $\mathrm{m} / \mathrm{migrant}$ family is something that you have to be proud of because your parents want the best for you, for example, education and they do everything they can to maken want the life " In addition to refore you succeed in life." In addition to referencing the importance of being treated equall and that "skin color, culture or beliefs" should not matter, Aracely also invites other within her school and the larger Mountain Valley local community to realize how her $\mathrm{im} /$ migrant parents have some of the same goals for education that other pare her and "want the best" for their children and will "do everything they can to ments do succeed in life."

Student participants shared common stories of the difficulties they faced in learning English and communicating with peers, teachers, and other members of the loca community. Threaded throughout their responses was a clearly stated invitation for others to understand the obstacles they faced and directly intervene when they wor being bullied, hares could could support and stand up for them was intimately linked to their claims for humanity as im/migrants. Given these invitations reflect both a desire to humanize and desire to resist unjust treatment, they embody a critical race ethnic that affirms experiential knowledge in efforts to disrupts institutional racism. Furthermore, in ex context of this research finding, micro-invitations political boundaries of belonging. As a invitations also signaled a call to reconsider conveying how they felt, but also fforts that contribute to feelings of mast thality.

Theme 3: The importance of im/migrant families as a source of community cultural wealth. Many student participants also shared personal stories of the strength of thral families and how their families helped them through the difficulty of trengths of their new school and community. Student the difficulty of transitioning to a ience they, their siblings, and their parents exhibited in leavized the tenacity and resilsometimes under extrardinary parents exhibited in leaving their country of origin, cleansing, and arriving in tinary circumstances such as war, famine, and ethnic leansing, and arriving in the U.S. to start their lives all over again.

The process of identifying challenges gave student participants multiple opportunities to consider what assets they had as individuals, within cultural group to cultural group to address those challenges and overcome them. Throughout their conversations with project facilitators and each other, students invited their fellow students and teachers to recognize and appreciate the community cultural wealth they and members of their family possessed at home and at school. For example, Juan Carlos, a student from Mexico, writes, "The most challenging part of being that we are expected to learn different kinds of words people knew about ELL is that we are smarter bords that we don't know. What I wis stereotypes he heard about not being inter because we are bilingual." In response to learning English "for a know English or not new lo new language. By stressing how learning English as a second language or, in some cases, as a third or fourth language was an intellectual challenge, Juan or, in some clear that being bilingual generates linguistic capital (Yosso, 2005). Juan Carlos makes

Students alo identified the support their families and cultural groups

In spite of difficulties the support their families and cultural groups provided them. as a source of strength as a source of strength, pride, and shared identity. Lizeth writes:
What is special about my $\mathrm{im} /$ migrant family is that we like to stay together. The Whallenging part that my family and I have to overcome is that we don't have family in the U.S.A. with us, we're alone in this country. I would describe my home life and culture as powerful, strong and united. When I am at home and with my family, we like to eat together, dance, go outside, listen to music, and have fun.

Ruben, another ELL student from Mexico, shared that he too is proud of his family and the familial and cultural strengths, or familial capital (Yosso, 2005), they bring to school and to the local community. He demonstrates how micro-invitations provide a critical opportunity to define himself and his family. He writes:

What I want to people to know about my home life is I am proud to be a part of a Mexican family and my culture. When I am at home and with my family, I like to play with them board games and talk about school and work. Something special about my family is that every weekend we go to the park playing some baseball or we have a barbecue. What I love about my home life and culture is we always do are tradition as a Catholic and Mexican people even that we are here in the U.S.A.

Equally for Muslim students, their photovoice projects and interviews gave them an opportunity to highlight many positives about their families and the strengths of their culture. Jabr, a student from Iraq, writes that "What I love about my home life and culture is we live together and we don't leave each other. We are a Muslim family. We like it because it's the right religion for us. I would describe my home life and culture as a happy, supportive Muslim family!" Mazin, another student from Iraq, spoke directly back to some of the deficit-laden myths he had heard at school and in the U.S. about being a Muslim. He stated, "I am proud to be Muslim, because my religion represents peace, love, respect and many other things. I want people to understand Islam and know that we aren't terrorists and that we are good citizens."

In their posters, both Jabr and Mazin wanted to point out that their families and culture were full of love and support for one another and not reflective of negative stereotypes Both students expressed the idea that they hoped their fellow students and teachers would see them as "good citizens" rather than as "terrorists." Moutaz, a student from Libya, saw his family and home culture as a source of strength during the difficult times he faced as he readjusted to life in school in the U.S. He writes, "It is a hard job to quickly blend in to the American culture. What is special about my home culture is that it gives me purpose in life while trying to adapt to the U.S. culture and fit in." Moutaz sees his family as a way to provide purpose and stability in the face of the conflicting and often problematic ways in which he often felt received by students and teachers at his school.

In addition to the perspectives shared here by Jabr, Mazin, and Moutaz, that they wanted to let other students know they weren't "terrorists" but "good citizens", other students from Arabic- speaking communities also felt compelled to share their own personal reflections about racially- and religiously-based discrimination. Against a largely deficit-based perspective, the students chose, on their own, to actively resist the majoritarian narrative of Muslims as a threat. Instead, they highlighted the strengths of their families, the pride they feel in their religion as one of peace, love, and respect, and their shared community cultural wealth.

Theme 4: An invitation for patience and understanding. One poignant theme student participants expressed during the project was for peers, teachers, and community members to increase their levels of patience as they adjusted to their new school. 
Students often made direct invitations to others to deepen an understanding and appreciation of their effort to succeed in school as new arrivals to the U.S.

Brenda, a student from Mexico, wrote, "The most challenging thing for me at school has been learning English. I wish all people knew that English Language Learners are really smart but sometimes we don't understand the language and it may seem to others that we are lazy." Brenda here juxtaposes two ideas about English Language Learners such as herself. On the one hand, people at school might think that English Language Learners don't understand English and that they are lazy for not quickly becoming proficient in English. On the other hand, she invites others at school to understand "that English Language Learners are really smart." In her poster, she has included a photo she took of geese taking flight out of a pond. She writes, "The geese in this picture represent freedom to me because I also love freedom and I want to be able to do the things I love without being afraid of what people will say or think about me." Brenda wishes she could "take flight" in school and as a new member of the local community, but struggles to deal with the fear of "what people will say or think" about her because she is an English language learner.

Eduardo, another student from Mexico, also writes about how English Language Learners adjust to life in the U.S. He writes, "We see things differently, we think differently, we eat different food. We speak differently and our brain works differently, but when you put those things together and then you match it with other cultures and languages you get something like this book [a reference to a book image he has in poster]; now you are more open to another person's thinking and you mature more as a person." By describing his life as a book that has yet to be written, Eduardo illuminates the potential of what's to come, of becoming someone who proudly reflects his culture, language, thinking, and maturation. But this requires a collective commitment from peers, teachers, and the local community. Like other im/migrant students, he calls on his teachers for support and for patience. This not only requires teachers to reconsider their pedagogical pace, but also reconsider the struggles and resources of $\mathrm{im} / \mathrm{migrant}$ students.

\section{Discussion}

One important finding of this photovoice research project were the many ways in which im/migrant students wanted to both describe their lives in and out of school, but also invite their peers, teachers, and members of the local community to better understand their unique situations and contexts of reception in the U. Im/migrant students in the project experienced daily microaggressions that embodied deficit discourses about themselves. Photovoice allowed them to counteract these problematic beliefs through their own words, images, and text. They continually shared that they wanted their peers and teachers to see how much they valued their educational growth. They also wanted to let others know about the multifaceted strengths and cultural resources evident in their lives in school and home communities. In the examples provide above, we have highlighted several ways in which high school students in this study intentionally and purposefully invited teachers, fellow students, and members of their community into their lives as an intervention to disrupt erroneous, oppressive, and racist ideologies about who they are as Im/migrants and Students of Color. We have named these intentional ways in which these students signa to others their desire to be better understood and valued in school as micro-invitations.

We believe that members of marginalized groups, in this case, im/migrant high schoo students are responding at all times to the different forms of oppression they face and, 278 through their responses, are inviting members of the dominant group to critically understand who they are, particularly through as asset-based and community cultura wealth frame (Yosso, 2005). The concept of a micro-invitation centers the analysis on the discursive response by a member of a marginalized group to (re)cast and (re)frame the ways in which we view the marginalized. Our findings suggest micro-invitations are strategic interventions core to counter-storytelling, expanding critical race approaches for challenging majoritarian stories about Communities of Color (Solorzano \& Yosso, 2002). In highlighting them as tactics for intervening and disrupting deficit discourses, we seek to extend our understanding of how counter-narratives are employed within schools by youth as opportunities to build collective forms of resistance.

Despite clearly identifying ways in which they experienced feelings of pain, lonelines and disconnectedness from school, student participants still wanted to be accepted into the school community and included in the life of the school by their peers and teachers. They expressed a need to feel accepted in school contexts that had not felt welcoming to them. This underlying need for acceptance is an important finding in that it underscores the work that teachers, school administrators, and counselors need to intentionally and conscientiously do in schools to create supportive and authentic forms of engagement and connection with students from im/migrant backgrounds. Though schools may already have support systems in place for new im/migrant students, such as new student orientation or student mentor programs, the need for more comprehensive and intentional programs for im/migrant students is clear from the student participants in this study.

The findings of this study also provide insight into the ways im/migrant students relied upon and recognized the community cultural wealth (Yosso, 2005) of their families in the face of tremendous adversity, as well as their hope that others could see the resources and determination they bring. In response to the stereotypes about their families, students explicitly pointed out how their families provided them with love, support, and encouragement and different kinds of funds of knowledge (Moll, Amanti, Neff, \& Gonzalez, 1992) that supported and sustained them through challenges. Students from Muslim backgrounds in particular pointed out how their religion was actually one based upon "peace, love, [and] respect" and invited fellow students and teachers to see them as "good students" and families, rather than as terrorists.

Finally, student participants invited teachers, counselors, principals, and fellow students to be patient and understanding of the difficulties they face in learning English and re-establishing themselves as successful students in their new communities and schools. Students clearly expressed the desire for others to treat them as intelligent, resourceful people who can succeed if other people are willing to be patient and understanding as they seek to become successful in school.

Throughout the project, im/migrant students invited others to critically understand their struggles, acknowledge the resources and perseverance they bring to school, and intervene to disrupt racist ideologies and practices. Through micro-invitations, student participants utilized discursive strategies to call out distorted and inaccurate portrayals of im/migrants in the U.S. while simultaneously calling in teachers, peers, and others to provide support, deepen their understanding, and fundamentally act in ways that further justice for im/migrant students, their families and communities. 


\section{References}

Bagnoli, A. (2009). Beyond the standard interview: The use of graphic elicitation and arts-based

Baldridge, B., Hill, M., \& Davis, J. (2011). New possibilities: (Re)engaging Black male youth within

Baszile, D. (2009). Deal with it we must: Education, social justice, and the curriculum of hip hop culture.

Bates, D. (2010). The memory of photography. Photographies, 3(2), 243-257.

Bell, L., \& Desai, D. (2011). Imaging otherwise: Connecting the arts and social justice to envision and act for change. Equity and Excellence in Education, 44(3), 287-295

Booth, M., \& Sheehan, H. (2008). Perceptions of people and place: Young adolescents' interpretation of their
schools in the United States and the United Kingdom. schools in the United States and the United Kingdom. Journal of Adolescont Research, 23(6), 722-744. Cammarota, J., \& Aguilera, M. (2012). "By the time I get to Arizona": Race, language, and education in

Charmaz, K. (2006). Constructing grounded theory: A practical guide through qualitative analysis. Thousand Oaks, CA: Sage,

Corbin, J., \& Strauss, A. (2008). Basics of qualitative research (3rd ed.). Thousand Oaks, CA: Sage.

DeCapua, A., Smathers, W. \& Tang, L.F. (2007). Schooling, Interrupted. Educational Leadership, 64(6), 40-46. Delgado, M. (2012). Urban youth and photovoice: Visual ethnography in action. New York, NY: Oxford

Delgado, R. \& Stefancic, J. (2001). Critical race theory: An introduction. New York: New York University Press.

Doda, N., \& Knowles, T (2008). Listening to the voices of adolescents. Middle School Journal, 39(3), 26-33. Duncan-Andrade, J. (2005). Developing social justice educators. Educational Leadership, 62(6), 70-73.

Eldsen-Clifton, J. (2006). Constructing "thirdspaces": Migrant students and the visual arts. Studies in Learning, Evaluation, Innovation, and Development, 3(1), 1-11.

Esposito, J., \& Swain, A. (2009). Pathways to social justice: Urban teachers' use of culturally relevant pedagogy as a conduit for teaching social justice. Perspectives on Urban Education, 6, 38-48.

Ewald, W., \& Lightfoot, A. (2001). I wanna take me a picture: Teaching photography and writing to children Boston, MA: Beacon Press.

Fergus, E. (2009). Understanding Latino students' schooling experiences: The relevance of skin color among Mexican and Puerto Rican high school students. Teachers College Record, 111(2), 339-375.

Foster-Fishman, P., Law, K., Lichty, L., \& Aoun, C. (2010). Youth reACT for social change: A method for youth participatory action research. American Journal of Community Psychology, 46(12), 67-83.

Freire, P. (1970). Pedagogy of the oppressed. New York, NY: Continuum.

Gay, G. (2010). Culturally responsive teaching: Theory, research, and practice, $\left(2^{\text {nd }}\right.$. Ed.). New York, NY: Teachers College Press.

Gillborn, D. (2006). Rethinking white supremacy - who counts in "whiteworld." Ethnicities, 6(3), 318-340. Gosessling, K., \& Doyle, C. (2009). Thru the lenz: Participatory action research, photography, and creative process in an urban high school. Journal of Creativity in Mental Health, 4(4), 343-365.

Gubrium, A., \& Torres, M. (2013). The meaning is in the bottle: Latino youth communicating double standar ideologies through photovoice. American Journal of Health Education, 44(3), 146-155.

Griebling, S., Vaughn, L., Howell, B., Ramstetter, C., \& Dole, D. (2013). From passive to active voice: Usin photography as a catalyst for social action. International Journal of Humanities and Social Science, 3(2) 16-28.

Ho, W., Rochelle, T., \& Yuen, N. (2011). "We are not sad at all”: Adolescents talk about their "City of Sadness" through photovoice. Journal of Adolescent Research, 26(6), 727-765.

Holdaway, J., \& Alba, R. (2009). Introduction: Educating im/migrant youth: The role of institutions and agency. The Teachers College Record, 111(3), 597-615.

Jimenez, R., \& Rose, B. (2010). Knowing how to know: Building meaningful relationships through instruction that meets the needs of students learning English. Journal of Teacher Education, 61(5), 403-412.

Kaplan, I., \& Howes, A. (2004). "Seeing through different eyes": Exploring the value of participative research using images in schools. Cambridge Journal of Education, 34(2), 143-155.

Krogstad, J.M. \& Fry, R. (2014). Dept of ed. projects public schools will be 'majority-minority' this fall. Pew Hispanic Research Center. Retrieved from https://www.pewresearch.org/fact-tank/2014/08/18/u-s-public schools-expected-to-be-majority-minority-starting-this-fall/

Lambert, J. (2013). Digital storytelling: Capturing lives, creating community. New York, NY: Routledge.

Leech, N. L., \& Onwuegbuzie, A. J. (2008). Qualitative data analysis: A compendium of techniques and framework for selection for school psychology research and beyond. School Psychology Quarterly, 23, $587-604$.
Luttrell, W. (2010). "A camera is a big responsibility": A lens for analyzing children's visual voices, Visuo

McInerney, P. (2009). Towards a crucial pedagogy of engagement for alienated youth: Insights from Freire .

Moje, E. (2008). The complex world of adolescent literacy: Myths, motivations, and mysteries. Harvard Educational Review, 78(1), 107-154.

Moll, L. C., Amanti, C., Neff, D., \& Gonzalez, N. (1992). Funds of knowledge for teaching: Using a qualitative approach to connect homes and classrooms. Theory Into Practice, 31(2), 132-141.

Morrell, E. (2007). Critical literacy and urban youth: Pedagogies of access, dissent, and liberation. New York, NY: Routledge.

Murrell, P. (2006). Toward social justice in urban education: A model of collaborative cultural inquiry in urban schools. Equity \& Excellence in Education, 39(1), 81-90.

Ozer, E., Ritterman, M. \& Wanis, M. (2010). Participatory action research (PAR) in middle school. America Journal of Community Psychology, 46(1-2), 152-166.

Paris, D. (2011). 'A friend who understand fully': Notes on humanizing research in a multiethnic yout community. International Journal of Qualitiative Studies in Education, 24(2), 137-149,

Pérez-Huber, L. \& Solorzano, D. (2015). Vizualizing everyday racism: Critical race theory, visua microaggressions, and the historical image of the Mexican banditry. Qualitaitwe Inquiry, 21(3), 223-238. Pierce, C. (1970). Offensive mechanism. In F. Barbour (Ed.), The Black seventies (pp. 265-282). Boston, MA Porter Sargent.

Roxas, K., \& Gabriel, M. (2016). Amplifying their voices. Educational Leadership, 73(5), 78-83.

Sanchez, P. (2010). In between Oprah and Cristina: Urban Latina youth producing a countertext with participatory action research. Social Justice, 36(4), 54-68.

Seidl, B. (2007). Working with communities to explore and personalize culturally responsive pedagogies "Push, double images, and raced talk." Journal of Teacher Education, 58(2), 168-184.

Smith, L., Davis, K., \& Bhowmik, M. (2010). Youth participatory action research groups as school counselin interventions. Professional School Coun

Smith, L. T. (1999). Decolonizing methodologies. New York, NY: Zed Books.

mith, W. A. (2004). Black faculty coping with racial battle fatigue: The campus racial climate in a post-civil . In D. Cleveland (Ed.), A long way to go: Conversations about race by African American faculty and graduate students (pp. 171-190). New York: Peter Lang.

mith, W. A. (2008a). Campus wide climate: Implications for African American students. In L. Tillman (Ed) A handbook of African American education (pp. 297-309). Thousand Oaks, CA: Sage.

mith, W. A. (2008b). Higher education: Racial battle fatigue. In R. T. Schaefer (Ed.), Encyclopedia of race ethnicity, and society (pp. 615-618). Thousand Oaks, CA: Sage.

Smith, W. A. (2010). Toward an understanding of Black misandric microaggressions and racial battle fatigue in historically White institutions. In V. C. Polite (Ed.), The state of the African American male in Michigan: A courageous conversation (pp. 265-277). East Lansing: Michigan State University Press.

Smith, W. A., Yosso, T. J., \& Solorzano, D. G. (2007). Racial primes and Black misandry on historically White Quarterly, 43, 559-585.

Solorzano, D.G. Ceja, M. \& Yosso, T. (2000). Critical race theory, racial microaggressions, and campus racial Solorzano, D.G., Ceja, M., \& (2002). Critical race methodology: Counter-storytelling as an analytical Solorzano, D. G., \& Yosso, T. J. (2002). Critical race methodology:
framework for education research. Qualitative inquiry, $8(1), 23-44$.

Stovall, D. \& Delgado, N. (2009). "Knowing the ledge": Participatory action research as legal studies for urban Stovall, D., \& Delgado, N. (2009). "Knowing the ledge": Participatory action

Strack, Magill \& McDonagh. (2004). Engaging youth through photovoice. Health Promotion Practice, 5(1), 4958.

Suárez-Orozco, C. Pimentel, A., \& Martin, M. (2009). The significance of relationships: Academic engagement and achievement among newcomer immigrant youth. Teachers College Record, 111(3), $712-749$.

Suárez-Orozco, C. \& Suárez-Orozco, M. (1995). Transformation: Migration, family life, and achievement motivation among latino adolescents. Stanford, CA: Stanford University Press.

Suárez-Orozco, C. \& Suárez-Orozco, M. (2009). Children of immigration. Cambridge, MA: Harvard University Press.

Streng, J., Rhodes, S., Ayala, G., Eng, E., Arceo, R., \& Phipps, S. (2004). Realidad Latina: Latino adolescents, their school, and a university use photovoice to examine and address the influence of immigration. Journal of Interprofessional Care, 18(4), 403-415.

Torre, M., Fine, M., Alexander, N., \& Genao, E. (2007). "Don't die with your work balled up in your fists": Contesting social injustice through participatory research. In B. Ross Leadbeater and N. Way (Eds.), Urban Girls Revisited. (221-242) 
Villegas, A., \& Lucas, T. (2007). The culturally responsive teacher. Educational Leadership, 64(6), 28-33. Wang, C. (1999). Photovoice: A participatory action research strategy applied to women's health. Journal of Women's Health, 8(2), 185-192.

Wang, C., Cash, J., \& Powers, L. (2000). Who knows the streets as well as the homeless?: Promoting personal through photovoice. Health Promotion Practice, 1(1), 81-89.

Yosso, T.J. (2005). Whose culture has capital? A critical race theory discussion of community cultural wealth. Renke, Ethnicity, and Education, 8(1), 69-91.

Zenkov, K. (2009). The teachers and schools they deserve: Seeing the pedagogies, practices, and programs Zenkov, K., \& Harmon, J. (2009). Picturing a writ (2), 168-175.

to urban you h. Jon, . (2009). Picturing a writing process: Using photovoice to learn how to teach writing

698

PBO 